[Bull. Agr. Chem. Soc. Japan, Vol. 21, No. 4, p. 261 262, 1957]

\title{
On the Studies of Angustmycins
}

\section{Degradation Studies of Angustmycin A}

Sir :

In the previous report1), the existence of adenine as a structural fragment in angustmycin A was indicated spectrographically, while the other moiety was presumed to be a sugar. The acid cleavage of the antibiotic under mild condition yielded adenine (I), and a new sugar (II), to which the name angustose was proposed. However, under a more vigorous condition, instead "angustose", allomaltol (III) was obtained, which was proved to be an acid decomposition product of angustose.

The characterization and identification of these three compounds are reported in this paper.<smiles></smiles>

(I)<smiles>CC1C=C(O)C(O)CO1</smiles>

(III)
When angustmycin $\mathrm{A}$ was subjected to hydrolysis with $1 / 10 \mathrm{~N}$ hydrochloric acid in a boiling-water bath for 30 minutes, the hydrolysate gave a positive intensive Fehling, ammoniacal silver nitrate reactions. On treatment of the hydrolysate with cation exchange resin Amberlite IR 120, successively with the anion exchange resin Amberlite IR $4 \mathrm{~B}$, a neutral solution was obtained, which was concentrated in vacuo to yield a pale yellow syrup. When this syrup was further purified by cellulose powder partition chromatography with water saturated butanol, a crystalline substance of melting point $116-118^{\circ}$ (dec.), $[\alpha]_{\mathrm{D}}^{30} 18^{\circ}$ (c, $1 \%$ in ethanol) was ob-

1) Hsii Yüntsen, K. Okuma, Y. Ishii and H. Yonehara, tained. The tentative formula $\mathrm{C}_{60} \mathrm{H}_{10} \mathrm{O}_{5}$ was derived from elemental analysis. Anal. Calc. for $\mathrm{C}_{6} \mathrm{H}_{10} \mathrm{O}_{5}: \mathrm{C}, 44.44 ; \mathrm{H}, 6.22$. Found : $\mathrm{C}$, $44.18 ; \mathrm{H}, 6.40$.

The crysralline substance gave positive Fehling, Molish, ammoniacal silver nitrate, anthrone and iodoform reactions.

The Kuhn-Roth determination indicated the presence of one $\mathrm{C}-\mathrm{CH}_{3}$ group. The infrared absorption spectrum exhibited bands at $3450 \mathrm{~cm}^{-1}, 1710 \mathrm{~cm}^{-1}, 1210 \mathrm{~cm}^{-1}, 1160 \mathrm{~cm}^{-1}$, $1120 \mathrm{~cm}^{-1}, 1066 \mathrm{~cm}^{-1}, 1040 \mathrm{~cm}^{-1}, 935 \mathrm{~cm}^{-1}, 910$ $\mathrm{cm}^{-1}$, and $780 \mathrm{~cm}^{-1}$. On the basis of these results this substance was considered to be a natural occurring unknown sugar, named angustose. From the concentrated eluate of the cation exchange resin Amberlite IR-120 with $1 \mathrm{~N}$ hydrochloric acid, a crystalline needle was obtained as the hydrochloride $1 / 2$ hydrate, which melted at $284-286^{\circ}$ (dec.), and showing one peak of U.V. at $260 \mathrm{~m} \mu$. Anal. Calc. for $\mathrm{C}_{5} \mathrm{H}_{5} \mathrm{~N}_{5} \mathrm{HCl} \cdot{ }_{1}{ }_{2} \mathrm{H}_{2} \mathrm{O}$ : C, 33.2; $\mathrm{H}, 3.9: \mathrm{N}, 38.8 ; \mathrm{Cl}, 19.6$. Found: $\mathrm{C}, 33.3 ; \mathrm{H}$, $3.8 ; \mathrm{N}, 38.7 ; \mathrm{Cl}, 19.55$.

On treatment of this crystalline hydrochloride in aqueous solution with the anion exchange resin to remove hydrochloric acid, the free base was obtained as needles, which decomposed at the range over $350^{\circ}$ (in an air bath) showing one absorption peak of U.V. at $260 \mathrm{~m} \mu$. (E 13000). Anal. Calc. for $\mathrm{C}_{5} \mathrm{H}_{5} \mathrm{~N}_{5}$ : $\mathrm{C}, 44.44 ; \mathrm{H}, 3.73$; N, 51.83. Found: C, 44.38; $\mathrm{H}, 3.87$; N, 51.83.

The identity of this crystalline base with adenine was confirmed by the coincidence of a IR spectrum.

Under a more acidic condition, such as with $1 \mathrm{~N}$ hydrochloric acid in a boiling-water bath, the hydrolysate showed an intense reddish color for 10 minutes, and almost all the 
angustose was found to be decomposed by the disappearance of its papergraphic spot at $R_{F}$ 0.40. (butanol: acetic acid: water, 4 : $1: 5, \mathrm{v} / \mathrm{v})$.

In addition to this fact, the appearance of a new spot at $R_{F} 0.82$ was recognized. The hydrolysate was extracted with ether at $\mathrm{pH}$ 2 , from which a crystalline substance was obtained. It sublimed at $110^{\circ}$, melted at 154 $156^{\circ}$, and gave an intense reddish-brown color with $\mathrm{FeCl}_{3}$. Anal. Calc. for $\mathrm{C}_{6} \mathrm{H}_{6} \mathrm{O}_{3}: \mathrm{C}, 57.14$; $\mathrm{H}, 4.76$. Found: C, 57.30; H, 4.78.

It was a weak acidic substance of pka. 8.25, and showed one U.V. absoption peak at 267 $\mathrm{m} \mu$ in $1 / 10 \mathrm{~N} \mathrm{HCl}(\varepsilon: 9800)$ which shifted to $307 \mathrm{~m} \mu$ in $1 / 10 \mathrm{~N} \mathrm{NaOH}$. $(\varepsilon: 5700)$. The IR spectra exhibited characteristic bands of $\alpha, \beta$, $\alpha^{\prime} \beta^{\prime}$ - unsaturated keton at $1665 \mathrm{~cm}^{-1}$, that of $>\mathrm{C}=\mathrm{C}<$ at $1610 \mathrm{~cm}^{-1}$.

The Kuhn-Roth determination gave one equivalent of $\mathrm{C}-\mathrm{CH}_{3}$. On the basis of these data, it was presumed to be one of the pyrones, and the identity with allomaltol (2methyl-5-hydroxy-4-pyrone) was confirmed by no depression of mixed melting point as well as the coincidence of IR spectrum with that of an authentic specimen.

The formation of allmaltol from angustose was proved by the degradation of the latter with $1 \mathrm{~N}$ hydrochloric acid, but the yield was not quantitative, being approximately $23 \%$ by spectrophotometrical determination.

Further work is now in progress and will be reported in a recent paper.

\section{Hsü Yuntsen}

Hiroshi YONEHARA*

Deparlment of Agricultural Chemisiry, Faculty

of Agriculture, University of Tokyo

Received May 24, 1957

* Insitiute of Applied Mirrobiology, University of Tokyo.

The Journal of Antibiotics. Ser. A, 9, 195 (1956). 